\title{
LOS LÍMITES DE LA TENTATIVA PUNIBLE. UNA PERSPECTIVA EPISTEMOLÓGICA. CON ESPECIAL REFERENCIA AL CÓDIGO PENAL ESPAÑOL DE 1995.
}

\author{
Jesús María Silva Sánchez \\ Catedrático de Derecho Penal \\ Universidad Pompeu Fabra
}

1. El artículo 16.1 del Código penal español de 1995 señala que "hay tentativa cuando el sujeto da principio a la ejecución del delito directamente por hechos exteriores, practicando todos o parte de los actos que objetivamente deberían producir el resultado, y sin embargo éste no se produce por causas independientes de la voluntad del autor". De la referida definición o, mejor, descripción de los supuestos de tentativa, cabe subrayar los siguientes aspectos. Por un lado, se ofrece una regla en cuanto al comienzo de la tentativa, esto es, relativa a la delimitación de actos preparatorios y actos ejecutivos, que coincide de modo casi textual con la del art. 3 del CP de $1973^{1}$.

Ello significa que la discusión doctrinal sobre este problema no se ve en absoluto alterada en sus términos por la entrada en vigor del nuevo Código penal. Al no tomar éste partido en la cuestión, ni proceder siquiera a delimitar de algún modo el marco del debate, pueden seguir sosteniéndose desde las tesis más formalistas, hasta las que optan por una base sustancialmente material. De todos modos, quizá convenga mantener en este punto una cierta dosis de escepticismo y aceptar la parte de razón que asiste a quien afirma que, por el momento, "en realidad no hay una solución válida para todos los $\operatorname{casos}^{112}$. Esto es, en otros términos, que no se ha hallado

1 En realidad, la única diferencia es el recurso al término "sujeto" donde antes se empleaba la expresión "culpable"

2 STS de 12 de julio de 1995, ponente Delgado García (Act. Pen. 596). En el caso se trataba de un individuo que, abordando a una joven "...luego de preguntarla la hora, la espetó que se subiera a la moto, que la iba a follar, y como la referida no hiciera caso a su propuesta, el procesado le dijo que iba en serio al tiempo que le exhibía una navaja con gesto amenazador, si bien la atacada reaccionó rápidamente $y$, aprovechando que el acusado seguia montado en la moto trial que conducía, pudo despistarle corriendo y esconderse en un portal. desde donde fue acompañada hasta el trabajo por un conocido". La sentencia, en su FJ $5^{\circ}$, señala:

"De lo antes expuesto se deduce la importancia que tiene el problema de la distinción entre los actos preparatorios y los de ejecución de un delito, pues de su solución depende el que, como regla general, un hecho quede impune o haya de ser penalmente sancionado, según que se considere que comenzó o no la correspondiente ejecución. La doctrina coincide en que para tal solución no basta acudir al mencionado elemento subjetivo, el dolo relativo al delito consumado (teoría puramente subjetiva), pues éste ha de concurrir tanto en los actos de ejecución como en los preparatorios, aunque se suele utilizar "el plan del autor" como elemento importante para, a través de él, junto con otros elementos objetivos, poder apreciar si la ejecución ha comenzado o no. Asimismo la doctrina actual no suele considerar suficiente la teoría objetivo-formal que considera iniciada la ejecución cuando ha comenzado a realizarse alguno de los elementos recogidos en el correspondiente tipo delictivo. Generalmente, se suele reconocer carácter ejecutivo a los actos inmediatamente anteriores a la acción típica cuando conducen directamente a tal acción. Esta teoría objetivo-formal parece demasiado estrecha. Tiene muchos adeptos la llamada teoría objetivo-material, que considera iniciada la ejecución cuando ha co- 
todavía un criterio que permita una aplicación mínimamente segura, sino que, más bien disponemos en esta materia de un mero arsenal de "topoi" argumentativos o de reglas pragmáticas, cuya aplicación al caso concreto se convierte en un proceso de gran dificultad.

En segundo lugar, el concepto de tentativa se delimita de modo tal que comprende los casos de tentativa inacabada y tentativa acabada; en concreto, se extiende también a la tentativa acabada fallida, abarcando por tanto la tradicional figura de la frustración. Esta desaparece del nuevo Código, de modo que todas las formas.de imperfecta ejecución quedan sujetas a un mismo marco penal, con independencia de que luego, en la determinación de la pena concreta, se tenga en cuenta su diverso grado de progresión, para lo que existen reglas específicas, a las que más adelante se hará alusión (art. 62).

Una modificación en la que unos han reparado más que otros es la que ha sustituido las expresiones "y practica todos los actos de ejecución que debieran producir como resultado el delito" (art. 3, II CP derogado, para la frustración) así como "y no practica todos los actos de ejecución que debieran producir el delito" (art. 3, III CP derogado, para la tentativa) por la de "practicando todos o parte de los actos que objetivamente deberían producir el resultado" (art. 16.1 para la tentativa inacabada y acabada). La referencia al resultado ( $\mathrm{y}$ no al delito) no es, a mi entender, incorrecta. En efecto, la tentativa también es un "delito", aunque no sea uno de los directamente tipificados en la Parte Especial. Pero, ciertamente, el recurso a la expresión "resultado" tampoco está exento de problemas. Si se interpreta en el sentido de "resultado material", se suscita la cuestión de qué hacer con los delitos de mera actividad, que quedarían al margen de la regulación. Si se interpreta, en cambio, en el sentido "jurídico" (como resultado de lesión o puesta en peligro del bien jurídico), se salva la anterior objeción, pero queda en pie el hecho de que también en la tentativa (al menos en la idónea) hay un resultado de peligro. De modo que habría que interpretar resultado como resultado del tipo de la Parte Especial, en los mismos términos correctores en que procedía interpretar el término delito del Código derogado. Por lo demás, es cierto que el recurso al término resultado dificulta aun más que la expresión del texto anterior la aplicación directa de las disposiciones reguladoras de la tentativa a los casos de supo-

menzado a estar en peligro el bien jurídico protegido por el delito de que se trate. Algunos se refieren al dato de la proximidad espacio-temporal, otros a la causalidad material como criterios reveladores del carácter ejecutivo de la acción dirigida al delito. Otro sector doctrinal habla de univocidad, reputando actos de ejecución los que inequivocamente conducen a la producción del delito, aunque este último criterio sirve sólo para revelarnos a través de la prueba de indicios la realidad del antes referido elemento subjetivo o dolo, necesario tanto para los actos de ejecución como para los preparatorios.

En realidad no hay una solución válida para todos los casos. Partiendo del plan del autor, que suele aparecer manifestado en la conducta objetiva observada, y del tipo de delito concreto de que se trate, si se ha iniciado un comportamiento que naturalmente (cuando no haya un elemento extraño interruptor) ha de llevar a la consumación, podemos considerar iniciada la ejecución, aunque ningún elemento típico se haya producido. Todos los elementos antes mencionados, que las distintas teorías reputan como decisivos según su particular punto de vista, han de valorarse en su conjunto para apreciar en cada caso si nos hallamos o no ante un inicio de la ejecución. En todo caso, hemos de tener en cuenta la expresión "directamente" que nuestro CP utiliza al definir la tentativa (art. 3. 3), que debe servir para restringir la excesiva amplitud con que en la práctica se suele aplicar esta forma de imperfecta ejecución de los delitos...". Con esta fundamentación se llega a la conclusión -desde luego, no indiscutible- de que no cabe apreciar tentativa de violación intimidatoria, sino tan sólo un delito consumado de amenazas de carácter condicional. 
sición errónea de la ausencia de los presupuestos de las causas de justificación (falta del elemento subjetivo de justificación). Pues si bien cabía afirmar (al menos con cierta argumentación analógica) que en tales casos no se ha producido el delito como hecho antijurídico, difícilmente puede sostenerse que no se haya producido el resultado.

En tercer lugar, se incluye una regla - expresión del fundamento legal de la sanción por tentativa- que reduce los casos de tentativa punible a aquéllos en que se realizan todos o parte de los actos que objetivamente deberían producir el resultado. En la inclusión del adverbio "objetivamente" - que ya se contenía en el Proyecto de 1994, a diferencia del de 1992- algunos observadores han pretendido advertir un intento de excluir la punibilidad de los casos de tentativa inidónea.

La sanción de los supuestos de tentativa inidónea se basaba -en el marco del Código derogado- en el art. $52,2^{2}{ }^{3}$. Para un sector doctrinal, dicho precepto, sin embargo, no introducía un concepto que abarcara supuestos de tentativa o frustración distintos de los ya contemplados en el art. 3 de dicho cuerpo legal, sino que constituía una mera regla de determinación de la pena para algunos de ellos. Otro sector, en cambio, entendía que en el referido artículo se fundamentaba la sanción de intentos no comprendidos en la definición del referido art. 3. Ello había dado lugar a cierta discusión sobre la legitimidad de dicho precepto ${ }^{4}$. En cualquier caso, sin embargo, conviene indicar que la conformidad del art. $52,2^{\circ}$ con la Constitución había sido establecida indirectamente-, en el marco de un recurso de amparo, por la STC $70 / 1985$, de 31 de mayo, ponente Pera Verdaguer ${ }^{5}$.

2. Ahora bien, toda consideración acerca del tratamiento jurídico-penal de la tentativa inidónea debe partir del hecho de que concurren al menos dos conceptos divergentes acerca de cuándo nos hallamos precisamente ante una tentativa "inidónea" ${ }^{116}$. En concreto, los autores integrados en corrientes subjetivistas sostienen un concepto de inidoneidad ex ante: según esto, serían tentativas inidóneas aquéllas en las que un espectador objetivo medio en la posición del sujeto contemplando ex ante la conducta del agente apreciaría la ausencia de peligrosidad, mientras que el agente, por algún motivo, las entiende peligrosas. Como puede pensarse, el principal problema de este concepto de tentativa inidónea radica en su delimitación respecto a las tentativas irreales ${ }^{7}$. Por otro lado, los autores integrados en corrientes más bien objetivistas, que en principio cabe estimar dominantes, entienden que la inidoneidad es un concepto que

3 Tras haberse establecido en el párrafo primero la regla de determinación de la pena de la tentativa, se añadía en el párrafo segundo del art. 52 que "la misma regla se observará en los casos de imposibilidad de ejecución o de producción del delito".

Cfr. el completo estudio de GONZÁLEZ CUSSAC, "Principio de ofensividad, aplicación del Derecho y reforma penal", en Poder Judicial 28, diciembre 1992, pp. 7 y ss., en especial, p. 10 y ss., 15 y ss.

5 Se trataba de un supuesto de tentativa inidónea de aborto con inidoneidad del objeto.

6 En realidad, tres, si es que incluímos un capitulo de "tesis mixtas": cfr. FARRÉ TREPAT, La tentativa de delito, Barcelona 1986, pp. 3 y ss., 277 y ss., 355 y ss. para el Derecho español; SOLA RECHE, La problemática asociada a la llamada "tentativa inidónea" de delito (tesis mecanografiada), La Laguna 1994, pp. 22 y ss., con la abundante bibliografía citada en ambas.

Lo pone de manifiesto SOLA RECHE, La problemática, p. 41. 
se determina ex post. Según este punto de vista, la tentativa inidónea muestra ex ante, según el juicio de un espectador objetivo medio en la posición del autor, peligrosidad; sin embargo, ex post se advierte la imposibilidad estructural de producción del resultado en el caso concreto ${ }^{8}$. A partir de esta determinación conceptual, hay quien sostiene la impunidad de tales tentativas inidóneas -igual que la de las tentativas inidóneas de la concepción subjetivista- , mientras que hay quien se inclina por su punición, rechazando, en cambio, la de las tentativas inidóneas de los subjetivistas.

En este segundo grupo cabría todavía incluir, como posición diferenciada -muy en especial, en España ${ }^{9}$-, la de de los autores que estiman punible la que denominan tentativa relativamente inidónea (básicamente en casos de inidoneidad de los medios), mientras que sostienen la impunidad de la que es aludida como tentativa absolutamente inidónea (fundamentalmente, en supuestos de inidoneidad del objeto y, eventualmente, de los medios $)^{10}$.

Obviamente, la existencia de los dos conceptos referidos ${ }^{11}$-así como la de las dos tomas de posición en cuanto a la punibilidad- obliga a plantear la cuestión general acerca de cuándo la tentativa debe ser punible y acerca de si esa punibilidad debe conectarse de algún modo a la constatación de su peligrosidad ${ }^{12}$.

3. Cualquier consideración sobre el ámbito de las tentativas punibles, así como sobre la relación entre éstas y las tentativas "peligrosas", debe partir de la idea de que todas las tentativas son, desde un juicio ex post, que tome como referencia la producción o no producción del resultado, plenamente inidóneas. En efecto, en la medida en que no han alcanzado la consumación, podrían estimarse realmente "no peligrosas", pues la no consumación sería reflejo de la existencia de un defecto estructural en la ejecución del plan que ha hecho imposible la consumación, por imperceptible que tal

Esta divergencia en cuanto al sentido ( $y$, por consiguiente, al alcance) de la expresión "tentativa inidónea" ha lastrado por ejemplo, según creo, el debate entre Mir Puig y Cerezo Mir en este punto. Cfr. por ejemplo CEREZO MIR, Curso de Derecho penal español, PG, I, 4ª ed., Madrid 1994, pp. 393 y ss., en especial notas 136 y 150; MIR PUIG, Derecho penal, PG, $4^{3}$ ed. Barcelona 1996, p. 346 y ss., en especial nota 59. Cfr. también, próximo al punto de vista de Cerezo, GRACIA MARTíN, "Política criminal y dogmática jurídico-penal del proceso de reforma penal en España", Actualidad Penal 18, 1994, pp. 348 y ss., 351 y ss.

Cfr. GONZÁLEZ CUSSAC, Poder Judicial 28, diciembre 1992, p. 17 y ss, sobre su origen en la polémica entre Groizard y Silvela, y p. 22 y ss., llegando ya a la conclusión de la impunidad de la denominada "tentativa absolutamente inidónea" en el marco del art. $52,2^{\circ}$ del Código derogado.

10 Cfr. RODRíguez MOURUllo, "Las fases de ejecución del delito", en Revista Jurídica de Cataluña. N² Extra 1980, pp. 5 y ss, p. 16, aludiendo a que ya el art. 9 de la Ley de Vagos y Maleantes contemplaba, a los efectos de la imposición de medidas de seguridad, los casos que no constituyan delito "por inidoneidad del medio o inexistencia del objeto". Sobre ello, llegando a la conclusión de que los casos de tentativa "absolutamente" inidónea son impunes en el marco del nuevo Código penal, QUINTERO OLIVARES, en Quintero Olivares (dir.), Comentarios al nuevo Código penal, Pamplona 1996, p. 121.

11 En lo sucesivo no se contemplará aquí la supuesta distinción entre tentativas relativamente y absolutamente inidóneas, por no compartirse las bases de tal diferenciación, que contempla el problema de la tentativa desde una perspectiva ex post, incluyendo, además, sólo determinados conocimientos en el juicio.

12 Uno de los trabajos más ilustrativos de los últimos años es el de TORío LÓPEZ, "Indicaciones para una concepción dualista de la tentativa", en AA.VV., Presupuestos para la reforma penal, La Laguna 1992, pp. 169 y ss. 
defecto resultara -para el autor o para cualquier tercero- ${ }^{13}$. Así pues, desde un punto de vista estrictamente objetivista -lo que podríamos calificar como "perspectiva del observador omnisciente" -, dado que éste sólo admitiría los conceptos de necesidad e imposibilidad, toda tentativa sería un caso de imposibilidad de consumación ( i sería un "delito imposible"!). En cambio, desde un punto de vista ex ante en el que se prescinda del baremo del espectador omnisciente, evidentemente sí cabe apreciar la existencia de tentativas peligrosas. De este modo se percibe con gran claridad que la formulación de "juicios de peligro" refleja directamente el desconocimiento humano y es, por tanto, expresión de un problema epistemológico más que de una realidad ontológica ${ }^{14}$.

4. Las dos tesis anteriores, sin embargo, no obligan necesariamente a afirmar la imposibilidad de distinguir ex post entre tentativas ex ante peligrosas. A partir de la realización de un juicio en el que introduzcamos más elementos que los presentes en el juicio ex ante, aunque aún no el hecho de la producción o no producción del resultado, podríamos sostener que hay tentativas que muestran todavía un peligro concreto ex post y otras que de ningún modo pueden conducir a la consumación (en las que no se puede formular el juicio de peligro ex post). Ello puede advertirse con claridad si entendemos que el juicio ex ante de peligro se realiza por el espectador objetivo en la posición del autor: en tal caso, se supone que el autor, aunque realmente no hubiera tal peligro, se encuentra en una situación de "error" (suposición errónea de peligro) invencible, suficiente para el juicio de peligro ex ante ${ }^{15}$. En cambio, el juicio ex post se realiza por el hombre medio al margen de la posición del autor, de modo que tal hombre medio (no necesariamente experto y mucho menos omnisciente) puede entonces advertir peligro (entonces, tentativa idónea) o bien no advertirlo (entonces, tentativa inidónea). De esta forma de ver las cosas discrepa la teoría subjetiva, para la que el juicio de peligro ex ante debe construirse no sobre la base de un hombre medio en la posición del autor, sino sobre la base del juicio del propio autor, aunque con alguna corrección ${ }^{16}$.

13

Cfr., por ejemplo, MIR PUIG, "Antijuridicidad normativa y antinormatividad", en El Derecho penal en el Estado social y democrático de Derecho, Barcelona 1994, p. 233.

14 Sólo en los casos en que hay intermediación de la libertad o en los sectores en los que rige el principio de incertidumbre podría hablarse de que ese peligro (esa probabilidad) es ontológica y no epistemológica. Aunque habrá quien sostenga que en tales ámbitos rigen ontológicamente leyes de necesidad (causales), de modo, también aquí, se trata de déficits del conocimiento.

15 Cfr. esta perspectiva, rigurosamente desarrollada, en BALDÓ LAVILLA, Estado de necesidad y legitima defensa, Barcelona 1994, pp. 113 y ss., en especial 116-119. Debe significarse, con todo, que la situación de "error invencible" (inverso) no es propia sólo de la tentativa inidónea, sino común a todas las tentativas que se quedan en eso. Con un matiz. En las tentativas inidóneas el error es invencible porque el hombre medio en la posición del autor habría compartido su juicio (aunque el mismo hombre medio, situado en otra posición, no lo compartiria). En las tentativas idóneas, el juicio del autor no sólo es compartido por un hipotético hombre medio situado en su posición, sino por cualquier hombre medio (en cualquier posición), excluidos, por tanto, los sujetos muy expertos ( $y$, por supuesto, el espectador omnisciente).

16 Comparto con el monografista SOLA RECHE la opinión de que los intentos más inteligentes realizados en los últimos tiempos son los de SANCINETTI, Fundamentación subjetiva del ilicito y desistimiento de la tentativa, Bogotá 1995, pp.123 y ss., 177 y ss., en Argentina; y en Alemania, STRUENSEE, "Tentativa y dolo" (trad. Serrano González de Murillo), "CPC 1989, pp. 405 y ss.; El mismo", "Dolo de causar y causalidad putativa" (trad. Serrano González de Murillo). ADPCP 1990, pp. 933 y ss. Y. en España, GRACIA MARTIN, "Política 
Así, se vincula la presencia de dolo a un cierto "sentido social típico" de la acción. Abundando en esta línea, se entiende por algunos autores que los errores nomológicos (esto es, sobre las leyes de experiencia que han de regir la incidencia de su conducta en el mundo exterior) del autor excluyen la posibilidad de formular un juicio de peligrosidad (de sentido social), y convierten el hecho en una tentativa irreal impune. En cambio, se estima que ello no sucede con los errores ontológicos del autor, esto es, sobre los hechos que se realizan, los cuales, aunque no fueran compartidos por el hombre medio, siguen fundamentando la posibilidad de atribuir relevancia al juicio de peligro formulado en virtud de los mismos (sigue existiendo "racionalidad") y de apreciar, en consecuencia, una tentativa inidónea punible ${ }^{17}$.

5. Personalmente, no comparto la perspectiva de la teoría subjetiva para restringir el subjetivismo de sus puntos de partida. Así, entiendo que hay errores ontológicos, cuya constatación no puede sino conducir a formular un juicio de ausencia de peligrosidad y a la caracterización del hecho como tentativa irreal impune. Así, por ejemplo, en los casos de errores ontológicos burdos: el enajenado A, que percibe erróneamente los hechos, cree que un árbol que tiene ante sí es una persona, y en concreto su enemigo $B$, así que procede a darle hachazos para "matarle" ${ }^{18}$. Por contra, hay errores nomológicos que podrían tener alguna relevancia. Así, por ejemplo, el error nomológico en que incurre una persona con coeficiente intelectual inferior al medio, pero que no es burdo, porque consiste, por ejemplo, en atribuirle capacidad para matar a algo que sólo tiene capacidad para herir de consideración, pero no para causar la muerte. Aparte de todo ello, en ocasiones no es fácil distinguir entre conocimiento de hechos y conocimiento de leyes ( $y$, por consiguiente, entre errores ontológicos y errores nomológicos $)^{19}$.

6. A primera vista, podría parecer que la diferencia entre la teoría objetiva y la teoría subjetiva consiste en que para la teoría objetiva sólo son constitutivos de tentativa los peligros reales, mientras que para la subjetiva también lo son, al menos, también ciertos peligros putativos. Sin embargo, creo que la primera tesis que a este respecto conviene sentar, y que deriva de lo ya expuesto, es que la diferencia entre lo real y lo putativo es de grado, de modo que al final la fijación de la frontera es cuestión valorativa y no, en absoluto, ontológica. La afirmación anterior merece, sin duda, una aclaración. En efecto, lo que denominamos real, en puridad no es necesariamente real (en el sentido "fuerte" del término), sino aparente, aunque es cierto que la calificación de "real" expresa un determinado (y superior) grado de consenso social respecto a la efec-

criminal y dogmática jurídico-penal del proceso de reforma penal en España". Actualidad Penal 18, 1994, pp. 348 y ss.

17

$18 Y$ no es necesario acudir a casos tan extremos: bastan otros en que se produzcan suposiciones erróneas de hechos, en virtud de déficits en la percepción, o por el contexto emocional en que se sitúa el sujeto.

19

Con todo suscribo la opinión de varios autores (que recoge últimamente SOLA RECHE, La problemática, p. 364 ) de que no es la misma la valoración que merece la conducta de quien dispara con una pistola descargada. creyéndola cargada (error en el que no incurriría el espectador objetivo en su lugar), que la de quien cree poder matar con pistolas sin munición. 
tiva existencia de aquello de lo que se trata. Así, la calificación de algo como "real" sería expresiva de la existencia de un consenso máximo sobre su existencia, consenso que luego iría descendiendo hasta llegar al supuesto del error burdo (tentativa irreal) ${ }^{20}$. En este supuesto, la hipótesis del autor sobre la existencia de algo carecería de un mínimo consenso. Toda esta cuestión guarda, por tanto, una clara relación, que conviene subrayar, con la idea de que es el consenso cultural alcanzado el que suministra el baremo de los juicios de valor inherentes a la tipicidad ${ }^{21}$.

7. Por otro lado, y desde una perspectiva en principio objetiva, podría considerarse, atendiendo a requerimientos de la teoría subjetiva, la cuestión del tratamiento que merecen errores objetivamente no invencibles del sujeto activo -pues el espectador objetivo en su posición no incurriría en ellos-, pero quizá personalmente sí invencibles, y en todo caso no burdos, pues afectan a cuestiones de grado, de cantidad, etc. Nos encontramos aquí ante casos de error vencible sobre los hechos por déficits cognitivos (menor perspicacia, por ejemplo) o emocionales (mayor agitación, menor frialdad o serenidad), los cuales, sin embargo, no parece que queden tan lejos del standard de tentativa idónea ex ante e inidónea ex post.

8. Sobre la base de las consideraciones efectuadas, podrían distinguirse los siguientes casos de tentativa, en atención a la apreciación de su peligrosidad:

a) tentativa cuya peligrosidad ex ante compartirían todos, desde cualquier posición, y que ex post se seguiría estimando normalmente peligrosa, por desconocerse (o, porque, aun conociéndose, es de muy compleja configuración) el porqué de la no producción del resultado. Sólo el espectador omnisciente o, por darle mayores visos de realidad, el sujeto muy experto (con conocimientos muy especiales de hechos o de leyes) advertiría que "no hay peligro". Este es el modelo de tentativa que se suele llamar por los objetivistas "real". En ésta, aunque ex post se determine la causa de la no producción del resultado, se hablaría de idoneidad por estos autores. Pero obsérvese que en puridad no hay tal "realidad": si el sujeto omnisciente o el muy experto podría advertir que no hay peligro, entonces resulta que éste no es "verdadero", real (en el sentido fuerte del término), sino que al juicio de peligrosidad "real" se llega por vía de consenso ${ }^{22}$.

20

De todos modos, téngase en cuenta que, paradójicamente, este caso, que describe el consenso mínimo, el mínimo de apariencia, puede ser precisamente expresión de un " peligro real", una realidad que no alcanza consenso en una época dada y en un lugar dado, pero que puede hallarlo en otra época o en otro lugar. Piénsese, sin ir más lejos, en las conductas de echar el mal de ojo o de utilización de medios "paranormales", hoy tenidos en el mundo occidental por "irreales", pero que en otras épocas, otras comunidades, o incluso ciertas subculturas en nuestro mundo occidental son tenidas por realmente peligrosas.

21

Todo esto es mucho más evidente, desde luego, en los tipos con elementos normativos de contenido jurídico o social.

22 La perspectiva que se sigue aquí, centrada en la distinción de diversos grados de consenso como lo especifico de las diversas clases de tentativa, es compatible con la que adopta la perspectiva del conocimiento o el error como lo más significativo en este punto. En efecto, la perspectiva del error se centra en la relación entre representación del sujeto y realidad. La perspectiva del consenso se centra, en cambio, en la relación entre representación del sujeto y representación de los demás sujetos. Ambas tienen un punto claro de encuentro en el hecho 
b) tentativa ex ante peligrosa y ex post no peligrosa. En realidad, esta tentativa es ex ante peligrosa sólo para el hombre medio (esto es, para cualquiera) en la posición (o desde la perspectiva) del autor, pero no para otros que contemplaran el hecho ex ante adoptando otras perspectivas u ocupando posiciones distintas. Así pues, cabe constatar una disminución del consenso en cuanto a la peligrosidad. Conviene, en todo caso, subrayar que entre este grupo de casos y el anterior caben hipótesis intermedias, en las que el juicio del espectador medio situado en la perspectiva del autor sería compartido por unos sujetos, ubicados en determinadas posiciones (por ejemplo, la de la víctima o la de un testigo meramente ocular) pero no por otros, que se encuentren, a su vez, en posiciones diversas (por ejemplo, la del que posee cierta información, etc). De modo que entre el grupo a) y el b) existe una relación de gradación, sin solución de continuidad.

Ya en este punto conviene subrayar, con todo, que, incluso desde la perspectiva ex ante, la peligrosidad de las tentativas contenidas en el grupo a) no es la misma que la de las integradas en el grupo b). Pues en las primeras el juicio de peligro ex ante lo compartirían sujetos situados en las más diversas posiciones; en realidad, todos, salvo el sujeto muy experto. En cambio, en las segundas dicho juicio sólo lo emitiría un hombre medio situado en la posición del autor. Luego, en realidad tiene sentido afirmar que, incluso ex ante, una tentativa idónea (grupo a) es más "peligrosa" que una inidónea (grupo b).

c) tentativa ex ante no peligrosa. En este caso, ni siquiera el hombre medio, en la posición del autor, compartiría el juicio de peligro que realiza el autor. Disminuye más el consenso, en la medida en que sólo sujetos con una configuración cognitivoemocional inferior a esa media (que expresamos en el constructo "hombre medio") compartirían tal hipótesis del autor. En este grupo cabría establecer diferencias sustanciales, dentro de los casos que comprende, entre aquéllos que resultan más próximos al grupo b) y los más próximos al siguiente grupo: el d).

d) tentativa claramente "irreal", aberrante, eventualmente supersticiosa. Sólo el autor y quienes compartieran su visión aberrante de la causalidad llegarían a una conclusión coincidente. El consenso aparece ahora como limitado a muy pocas personas, al menos en relación con la comunidad que previamente ha definido esa actuación como aberrante o, en su caso, incluso "supersticiosa"23.

de que nuestro acceso a la realidad se produce por la vía de representaciones de la misma, de tal manera que tomamos por "realidad" la representación dominante (por mayoritaria, en general) sobre la misma. En el ámbito de lo empírico ello puede aparecer como desfigurado en parte, en la medida en que parece que el conocimiento científico nos ha proporcionado ya "la" realidad. Sin embargo, aun siendo esto cierto en lo esencial. convendria no olvidar que la ciencia sólo describe una representación provisional (no irrefutable) de la realidad.

Por lo demás, en cuanto se abandona el ámbito de lo empírico para entrar en el ámbito de las realidades valorativas, normativo-sociales, parece claro que lo "real" no es sino el resultado de la representación generalizada.

23

Conviene subrayar la exigencia de una previa definición de lo que se entiende por supersticioso, esto es, a la inversa, de establecer una convención sobre cuáles son las leyes que se admiten como existentes y verdaderas. Tal definición es implícita, obviamente, y expresa convenciones muy marcadas por aspectos culturales, que va- 
9. Una vez relativizada del modo expuesto la diferencia entre lo real y lo putativo, será posible partir de que una determinada comunidad normalmente estimará que afectación al bien jurídico, injerencia en la esfera de organización ajena, en realidad sólo se da en el primer grupo de casos. En efecto, sólo en ese grupo de casos se da un amplio consenso sobre la peligrosidad, lo que, en términos estadísticos, además, se corresponderá con la auténtica mayor lesividad de estos casos. Ahora bien, en el segundo grupo y quizá también en algunos casos pertenecientes al tercero, esa misma comunidad puede sostener la existencia de algún motivo para sancionar penalmente el hecho, desde el punto de vista de la genérica seguridad de los bienes jurídicos ${ }^{24}$. En efecto, hechos de ese carácter comprometen el sentimiento subjetivo de seguridad en el uso y disfrute de los bienes; dicho de otro modo, aunque en términos estadísticos las perspectivas de lesividad ${ }^{25}$ serán muy inferiores a las del grupo anterior, no resultan irrelevantes $^{26}$. A estos efectos, lo que no se vería tan claro sería incluir en este ámbito sólo el segundo grupo y ninguno de los casos del tercero, que le resulten íntimamente próxi$\operatorname{mos}^{27}$.

\section{Así las cosas, cabría sentar las siguientes afirmaciones:}

a) En principio, lo que parece claro es que las tentativas inidóneas (en el sentido objetivista de la expresión) no pueden ser sancionadas igual que las tentativas idóneas. Ello, por mucho que se haya mostrado que la diferencia entre unas y otras es, en último término, cuantitativa y relacionada con el grado de consenso alcanzado por el juicio de peligro $^{28}$

rían de una época a otra y de unas regiones de la Tierra a otras. Así, por ejemplo, en la Edad Media, el "mal de ojo" formaba parte de la "reconstrucción social de la realidad", integrando, en definitiva, la "racionalidad de la época". Lo mismo sucede hoy en sociedades de corte no occidental (que no comparten el modelo racionalempirista) e, incluso, en segmentos de nuestras propias sociedades occidentales.

Sobre el consenso existente en la actualidad sobre la vigencia del "principio de lesividad" así como sobre el amplio disenso sobre las consecuencias aplicativas que del mismo pueden derivarse, FIORE, "Il principio di offensività", en L'Indice Penale 2 / 1994, pp. 275 y ss. En particular, este autor (p. 280 y 281-282) admite la compatibilidad del principio de lesividad con los delitos de peligro abstracto ( $\mathrm{i}$ e incluso presunto, siempre que no se trate de presunciones "iuris et de iure"!), asi como con la concepción de ciertas "funciones" como bienes jurídicos (p. 285).

Esto es lo que MIR PUIG, PG, $4^{a}$, p. 347 , señala cuando vincula la apariencia de idoneidad ex ante, propia de la tentativa inidónea, a la peligrosidad estadistica del hecho (esto es, su conformidad externa, en razón de su configuración, con el arquetipo de lo peligroso). Cfr. también TORIO LÓPEZ, en Presupuestos, p. 173 y 178 (aquí también aludiendo a la peligrosidad estadística).

Cfr. las distinciones de BALDÓ LAVILLA, Estado de necesidad, p. 117, nota 250.

28

Hasta qué punto la cuestión es de grado o de perspectiva lo pueden mostrar diversas variantes de uno de los casos de "inidoneidad del objeto" más sencillos: matar al ya cadáver. Este supuesto puede constituir una tentativa prácticamente equivalente a la idónea: ej., en el momento en que entra la bala (realmente letal) del sujeto $A$ en el cuerpo de la víctima, ésta ha fallecido (unos segundos antes), lo que logra acreditarse tras múltiples y complejas pruebas periciales ex post. Pero, por supuesto, también puede constituir una tentativa inidónea "convencional": ej. A dispara a B, estimándolo vivo, juicio que compartiría cualquiera en su lugar, si bien los que se encuentran junto a $B$ saben que ya ha fallecido (unos minutos antes). $Y$, en fin, puede constituir 
b) Merece consideración la tesis de que la tentativa inidónea en clave objetivista y algunas de las tentativas inidóneas subjetivistas (las más próximas a aquéllas) no deberían ser sancionadas por relación al bien jurídico contra el que, en la representación del autor -más o menos apoyada por terceros- , se dirigían, pero al que no han podido siquiera empezar a afectar según el juicio social separado de la perspectiva del autor. Quizá resultara, pues, más satisfactorio, siguiendo lo sostenido por un sector doctrinal, plantear su sanción como delito contra la libertad y seguridad de los ciudadanos en el disfrute de sus bienes jurídicos; pues respecto a tal bien jurídico colectivo, aunque de clara base individual, las tentativas inidóneas aparecen como tentativas precisamente idóneas. En ello se aprecia la base correcta de la teoría de la "impresión" ${ }^{29}$, si bien ésta, al igual que otras teorías modernas, tiene el inconveniente de poner la sanción en relación con la autoimposición del Ordenamiento Jurídico, o con la genérica confianza en su vigencia, con lo que acaba también distanciándose de un Derecho penal de protección de bienes jurídicos ${ }^{30}$.

c) Un caso especialmente complejo es el de aquella tentativa irreal, que lo es según la valoración dominante, pero cuya realización tiene lugar en el marco de un (sub-) grupo social que comparte la percepción desviada de la realidad que se halla en su base. Pues ciertamente puede surgir ahí alguna necesidad preventiva en términos de "impresión".

d) La conminación de la tentativa irreal, al igual que la de la tentativa inidónea, en principio carecen de sentido desde perspectivas intimidatorias, pues sus autores piensan, por definición, que sus actos son idóneos. De modo que, en lo que aquí interesa, la sanción de la tentativa idónea podría parecer suficiente desde este punto de vis$t^{31}$. La necesidad de pena más clara parece ser la que deriva de consideraciones de prevención especial y de prevención general de integración ${ }^{32}$. Sin embargo, soluciones declaración de estado peligroso e imposición de una medida de seguridad-como la que en su día ofreciera la Ley de Vagos y Maleantes (art. 9, 4ํ de la Ley de 4 de agosto de

una tentativa irreal (o supersticiosa): ej. A dispara a B, que se encuentra cadáver en el féretro (pues ha fallecido horas antes), por algún tipo de representación aberrante sobre su eventual supervivencia.

29 En la línea de lo que después sostendría la teoria de la impresión, ya BENTHAM, Compendio de los Tratados de legislación civil y penal, I, (con notas por D. Joaquín Escriche), $2^{\circledR}$ edic., Madrid 1839, p. 26, distinguía para todo delito entre un "mal de primer orden", que es el que recae inmediatamente sobre tal o tales individuos señalables, y un "mal de segundo orden", que es el que nace del primero y se extiende sobre toda la comunidad o sobre un número indefinido de individuos no señalables. En concreto, "alarma" es el temor o aversión a sufrir el mismo mal del que se acaba de ver un ejemplo. También, Compendio, tomo II, p. 6 y ss.

30 Críticamente, GONZÁLEZ CUSSAC, Poder Judicial 28, diciembre 1992, p, 24-25. Cfr. también, aunque con diversidad de perspectivas, SOLA RECHE, La problemática, p. 152 y ss.

31 De todos modos, es preciso subrayar que, desde una perspectiva de análisis económico, la punición de la tentativa inidónea introduce costes adicionales a los de la punición de la consumación y de la tentativa idónea, de modo que hace todavia más antieconómica la decisión delictiva. La sanción de la tentativa inidónea es, pues. eficiente. Sobre ello convendría extenderse algo más, lo que aquí no es posible.

32 Cfr., por ejemplo, TORIO LÓPEZ, en Presupuestos, p. 181, para acabar fundamentando la sanción de la tentativa inidónea como una "desviación político criminal imprescindible de la lógica de los principios fundamentada en la necesidad". 
1933) y actualmente sigue existiendo en el Derecho italiano parecen fuera de nuestro marco de discusión.

En efecto, el Art. 49, 20 CPI dispone que :"La punibilità è altresì esclusa quando, per la inidoneità dell' azione o per la inesistenza dell' oggetto di essa, è impossibile l' evento dannoso o pericoloso". En estos casos es posible, ex art, 49 últ. CPI, que el juez imponga al sujeto una medida de seguridad, por ejemplo, la de libertad vigilada.

11. La inclusión del adverbio "objetivamente" en el art. 16 CP 1995 permite, de entrada, fundamentar legalmente la impunidad de los supuestos de tentativa irreal. En efecto, la apelación a un baremo objetivo para decidir si los actos "deberían producir el resultado" excluye, sin duda, aquellos casos en relación con los cuales no se alcanza siquiera un mínimo consenso sobre la peligrosidad de la conducta. Algo que, en el plano legal, no estaba tan claro ni con la definición de tentativa del art. 3 CP 1973, ni, sobre todo, con la redacción del art. $52,2^{\circ}$ del mismo cuerpo legal, que extendía la regla de determinación de la pena de la tentativa a los casos "de imposibilidad de ejecución o de producción del delito", habiéndose discutido si definía situaciones no comprendidas en el propio art. 3 o venía vinculado por la definición contenida en dicho artículo y sus posibilidades interpretativas. El nuevo texto establece, pues, de modo claro la impunidad de supuestos que de modo prácticamente unánime se vienen considerando por la doctrina como no merecedores de pena. En esa medida, cabe subrayar que cumple una de las funciones de la codificación, cual es la de fijar el marco de la discusión ${ }^{33}$. A ello se añade la ventaja adicional de que deja a la discusión doctrinal, como a mi juicio procede, la ulterior precisión de qué debe entenderse por "objetivo" ${ }^{13}, 0$, mejor, donde se halla el límite de lo "objetivo". Ciertamente, -y dejando aparte la cuestión de cuál haya sido la "voluntas legislatoris" -que, por lo demás, no se ha hecho expresa- la "voluntas legis" no indica qué grado de intersubjetividad es preciso para lograr la objetividad a la que alude el nuevo art. $16^{35}$. Así pues, no es imposible sostener que el adverbio "objetivamente" sigue sin excluir de modo absoluto la punición de las tentativas inidóneas (en el sentido objetivista) e incluso, yendo más lejos, de algunas tentativas inidóneas (en el sentido subjetivista) próximas a aquéllas y que gozaran, por tanto, de un consenso relativamente amplio en cuanto al juicio de peligro ex ante ${ }^{36}$. Pues, desde el momento

33 Cfr., en este sentido, para el Proyecto de 1994, SOLA RECHE. La problemática, pp. 287 ss. Un juicio similar creo que cabría extraer de la toma de posición anterior de FARRÉ TREPAT, "Consideraciones dogmáticas y de lege ferenda en torno a la punición de la tentativa inidónea", en Estudios de Derecho penal y Criminología, Homenaje al Prof. Rodriguez Devesa, I. Madrid 1989, pp. 259 y ss., 278-279.

Desde qué perspectiva hay que apreciarlo

$35 \mathrm{Ni}$, desde luego, tampoco el momento en el que debe darse dicho grado de intersubjetividad. Tratándose de tentativa, parece que haya que situarse en el momento de realización de los actos ejecutivos.

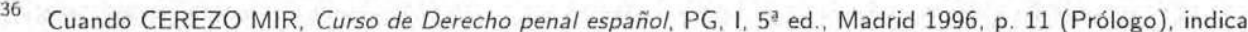
que en el nuevo Código penal ya no se castiga la tentativa inidónea, ello se refiere obviamente a la tentativa inidónea según el concepto subjetivista. Como a continuación añade, "en la nueva regulación de la tentativa se exige únicamente la peligrosidad de la acción desde un punto de vista ex ante, pero no la producción de un resultado de peligro, que un bien jurídico haya corrido realmente peligro". Cfr. sin embargo VIVES ANTÓN, en Vives (coord.), Comentarios al Código penal de 1995, I, Valencia 1996, p. 100: "donde la inidoneidad sea de tal naturaleza que impida, no ya en el caso concreto, sino según una consideración genérica, la consuma- 
en que la objetividad se define ex ante y, adicionalmente, no se indica que grado de intersubjetividad se requiere para alcanzarla, en ambos casos puede seguir afirmándose que el sujeto realiza actos que, según una cierta visión intersubjetiva ( $y$, por tanto, objetiva $^{37}$ ) van dirigidos a la producción del resultado ${ }^{38}$. Tal visión intersubjetiva sería, en el primer caso, la que tendrían todos los sujetos de características medias que compartieran la perspectiva del autor; o, en el segundo caso, la de buen número de sujetos (con nivel en muy poco inferior al del hombre medio por razones cognitivas o emocionales) quienes, asimismo, se situaran en la posición del autor ${ }^{39}$.

En esa medida por mi parte estimaría carente de base argumentativa la tesis según la cual el referido adverbio permitiría excluir también los supuestos de las denominadas tentativas absolutamente inidóneas (en particular, los de inidoneidad del objeto), aunque no los de las tentativas sólo relativamente inidóneas. Además de las consideraciones reseñadas y de los argumentos a los que se alude a continuación, conviene no abandonar, al considerar esta cuestión, una visión realista de las relaciones sociales y del papel del Derecho penal en el seno de las mismas.

12. La posibilidad interpretativa que exponemos no aparece desmentida, sino más bien reforzada, si atendemos a dos aspectos adicionales. Por un lado, si consideramos que, como ya antes se ha sugerido, una interpretación ex post de la objetividad, esto es, una determinación ex post de los "actos que objetivamente deberían producir el resultado" excluiría del ámbito del art. 16 a buen número de tentativas idóneas ${ }^{40}$. Y, sin embargo, no puede negarse que ello define el paradigma más incontestable de la "objetividad".

Que esto no responde a un puro conceptualismo alejado de la realidad lo ponen de relieve consideraciones como la de la STS de 29 de noviembre de 1995, ponente Hernández Hernánde $z^{41}$. Según el relato de hechos, Jerónimo, se había acercado a Francisco, para matarlo, poniéndole la pistola en la cara, pero éste" inmediatamente reaccionó protegiendo su faz con la mano

ción, no cabrá castigar la conducta como tentativa". Con todo, no es en absoluto fácil determinar qué pertenece a lo concreto y qué a lo genérico del hecho.

37 Vinculando también la "intersubjetividad" y la "objetividad", MIR PUIG, PG, $4^{a}$ ed, p. 347.

38 No muy lejano es, según creo, el punto de vista de MUÑOZ CONDE/ GARCÍA ARÁN, Derecho penal PG, $2^{3}$ ed. Valencia 1996, p. 440, entendiendo que cabrá la punibilidad en los casos en que con una consideración objetiva ex ante se admite que el sujeto podía razonablemente pretender la consumación del delito.

Un supuesto distinto es aquél en el que, debido a los conocimientos extraordinariamente superiores del sujeto activo, la conducta que ha dispuesto, orientada a la producción de la muerte de la víctima, no es interpretada "objetivamente" (intersubjetivamente) como apta para producir el resultado. Ello significará que, aunque alcance su objetivo, esto es, produzca la muerte, ni siquiera podrá ser interpretada como constitutiva de tentativa. Esta materia describe otro importante círculo de cuestiones, en el que no es posible entrar, pero que, en cierto modo subraya la propia coyunturalidad y consensualidad, ahora a propósito de sus consecuencias en el otro extremo, de la noción jurídico-penal de intento.

40 En realidad, excluiría a todas ( $i$ si el resultado no se ha producido es que objetivamente no debía producirse!). y el que se mantuviera a alguna tan sólo dependería del hecho de que no se lograra hallar la razón por la que el resultado no se ha producido. Lo que, obviamente, es por completo arbitrario.

Repertorio Act. Pen. 59 /1996. 
derecha, de suerte que uno de los dos disparos efectuados por el procesado impactara en la mano de Francisco y posteriormente rebotara en la mandíbula derecha de su cara...", de modo que éste sólo sufrió lesiones ${ }^{42}$. Pues bien, aunque la discusión en la sentencia afecta a si concurría una tentativa (como entendió la Audiencia) o una frustración (como resolvió el TS) es interesante observar en qué términos tiene lugar la argumentación, tratándose de un caso de manifiesta idoneidad (al menos, tal como la interpreta la doctrina dominante): "Al haber entendido el Juzgador a quo que el sujeto activo del delito objetivamente no ejecutó los actos necesarios y precisos para consumar el delito (...), aun cuando subjetivamente tuviera el ánimo de matar, para lo que utilizó un arma de fuego, las lesiones realmente causadas a la víctima del delito en ningún caso hubieran producido la muerte de la víctima por lo que no se puede mantener que realizó todos aquellos actos ejecutivos que eran precisos objetivamente para consumar el delito".

Por otro lado, si recurrimos a lo establecido en la regla de determinación de la pena de la tentativa en el nuevo Código. Así, el nuevo artículo 62 señala que "a los autores de tentativa de delito se les impondrá la pena inferior en uno o dos grados a la señalada por la Ley para el delito consumado, en la extensión que se estime adecuada, atendiendo al peligro inherente ál intento y al grado de ejecución álcanzádo". Los criterios de determinación judicial de la pena en la tentativa serán, pues, por disposición legal, el grado de ejecución y el contenido de peligro. El sentido de la referencia al "grado de ejecución" parece claro: se trata de la distinción entre tentativas inacabadas y acabadas, de modo que en principio ${ }^{43}$ se castiguen menos aquéllas que éstas.

Esto es importante, porque, como se advierte, no se establece una regla especial de determinación de la pena para la tentativa acabada fallida (frustración), que sí la tenía en el Código derogado en términos claramente agravatorios. Por tanto, las tentativas acabadas, tanto si son fallidas como si -todavía ${ }^{44}$ - no lo son, habrán de recibir la misma pena, pues el "grado de ejecución" es el mismo.

Ello, sin embargo, se expresa en términos los suficientemente flexibles como para que no deba castigarse necesariamente la tentativa inacabada con la pena inferior en

42 En la propia setencia se cita como muy similar el supuesto contemplado en la STS de 28 de mayo de 1994, en que el sujeto activo, tras haber apuntado a la cabeza del señor $\mathrm{E}$., le interesó la región submandibular izquierda "debido a un movimiento de rotación defensivo de la cabeza por parte de éste, causándole una herida en sedal, transversal al eje del cuerpo"

En efecto, este criterio debe combinarse con el otro, de modo que una tentativa acabada inidónea podría no castigarse con pena superior que una inacabada idónea.

En efecto, se dan casos en que, en el momento del enjuiciamiento, habiendo acabado la ejecución no es posible conocer todavía si el hecho se frustrará o se consumará. Quiere indicarse con esto que el de "tentativa acabada" no es un mero estadio temporal que inmediatamente se plasmará en frustración o consumación, sino que puede tener una prolongación en el tiempo y, en particular, ser objeto preciso del enjuiciamiento.

Ello se generalizará mucho más si se acoge, como es inevitable, un concepto personal de tentativa acabada y. en cambio, un concepto objetivo de frustración, como parece que procedía en el marco del Código derogado (cfr. RODRIGUEZ MOURULLO, RJCat extra 1980, p. 13). Pues entonces es obvio que en casos de codelincuencia pueden darse supuestos de tentativa acabada por completo distintos de la noción de frustración. El cambio legal, en suma, no puede estimarse huérfano de significado, pues pasa a centrarse en el aspecto personal del acabamiento de la aportación, en lugar de en el hecho objetivo de la frustración o no del hecho, para proceder a la determinación de la pena. 
dos grados. En efecto,el concepto de tentativa inacabada abarca desde el puro comienzo de la tentativa hasta el caso en el que sólo es preciso realizar un "acto" para culminar el proceso ejecutivo. De modo que no puede excluirse que tentativas inacabadas merezcan sólo la atenuación en un grado. Por lo demás, es obvio que este criterio debe combinarse con el siguiente para determinar finalmente el merecimiento y necesidad de pena de la tentativa en cuestión. Dicho segundo criterio, la referencia al "peligro inherente al intento" resulta más ambiguo. Por un lado, puede referirse a la toma en consideración de los diversos grados de peligrosidad "real" que pueden concurrir en el caso por encima del mínimo de peligro suficiente ex ante para determinar la relevancia típica. del intento; es decir, dar razón del aspecto cuantitativo del peligro ${ }^{45}$. Sin embargo, por otro lado, permite una interpretación que considere los diferentes grados de consenso sobre la peligrosidad de la conducta; desde esta perspectiva, se acogería el criterio de que la conducta sobre cuya peligrosidad existe menos consenso, dándose en todo caso el mínimo suficiente de peligrosidad intersubjetiva para adquirir relevancia típica, es menos peligrosa y puede (debe) ser sancionada con una pena inferior. Esta posibilidad interpretativa puede venir abonada por el hecho de que el Proyecto de 1992 acogía, en su regla de determinación de la pena de la tentativa (art. 58), el criterio de atender a la "seriedad del intento". Lo que sin duda alude al grado de intersubjetividad o al grado de consenso existente sobre la peligrosidad de la conducta del sujeto ${ }^{46}$.

Gimbernat, verbalmente, ha defendido el mantenimiento de la posibilidad de sancionar la tentativa inidónea sobre la base de la utilización en el texto legal de la expresión en condicional "deberían producir". En efecto, a su juicio tal expresión denota un juicio de probabilidad que necesariamente ha de ser subjetivo, partiendo del desconocimiento por parte del sujeto activo de las circunstancias concurrentes. Así pues, en los casos de ausencia de objeto o inidoneidad de los medios, se inclina por la punibilidad, que quedaría excluida tan sólo en los casos de desconocimiento por el autor de las leyes científico-naturales básicas. El argumento es, como se ve, de base fundamentalmente gramatical, pero coincidente en general con lo que aquí se viene sosteniendo.

13. Si bien la referida regla de determinación de la pena ya sigue esa línea -al menos según la interpretación expuesta-, parece claro que debe seguir discutiéndose la posibilidad de separar el régimen de las tentativas inidóneas (en el sentido objetivista, en general) del de las tentativas idóneas. En este sentido, merece discusión, entre otras, la propuesta de regularlas como delito de peligro contra la seguridad de los bienes jurídicos. Ahora bien, en tanto ese debate no tenga lugar, y a reserva de cuál sea su conclusión, la solución de posibilitar la sanción de las mismas en el marco de un concepto de tentativa concebido de modo amplio parece preferible a la total impunidad para ese grupo de conductas. Dado que el tenor literal de la ley no lo excluye tampoco, debe concluirse, pues, que el art. 16 del nuevo Código penal no impide la sanción de los supuestos de tentativa inidónea, en el sentido objetivista de esta expresión. Más discuti-

\footnotetext{
45 Por cierto que, desde tal perspectiva, puede haber tentativas inacabadas más "peligrosas" que otras acabadas

46 Cfr. sobre los criterios contenidos en la regla, VALLE MUÑIZ, en Quintero (Dir.), Comentarios, p. 389.
} 
ble es si en su seno caben incluso algunos supuestos de tentativa inidónea, según el concepto subjetivista de ésta, que resulten singularmente próximos a los de tentativa inidónea en sentido objetivo.

14. De todos modos parece inevitable que la nueva redacción tenga efectos en la práctica judicial. De hecho, ya podemos dar cuenta de un ejemplo: el constituido por la SAP Zaragoza (secc. $1^{\text {a }}$ ) de 24 de mayo de 1996, ponente Sr. Zubiri de Salinas ${ }^{47}$, al enjuiciar unos hechos que sin duda pueden calificarse como de variante del clásico caso académido "del tirador inexperto" (o caso de Thyrén). En el supuesto fáctico, tras un accidente en la autopista, Nicolás le reprocha a Isabel que la culpa del accidente ha sido suya. Hace ademán de golpearla con la mano, gritándole "te voy a matar" y "tú ya estás muerta". Ella se aleja del lugar, momento en que Nicolás "extrajo de entre sus ropas, concretamente de la cintura, un revólver con el que efectuó cinco disparos contra $\mathrm{M}^{2}$ Isabel, apuntando el arma hacia ella cuando ésta se hallaba a una distancia entre 15 y 20 metros, sin que ninguno de los proyectiles alcanzase a la mujer". Resulta probado por la corrrespondiente pericia que el revólver era, en principio, detonador, habiendo sido modificado para permitir el uso de munición con bala del calibre 22, "siendo correcto el mecanismo de

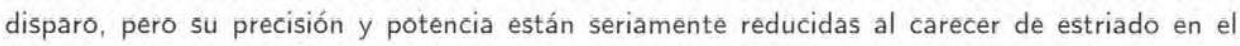
ánima, tener gran pérdida de gases a la entrada del cañón y ser el diámetro interior del cañón superior al de las balas, de modo que resulta efectivo a distancias inferiores a dos metros; a seis metros la precisión y energía están muy afectadas, y a una distancia superior a seis metros el acierto en el disparo se produciría sólo por casualidad y el proyectil incidiría sin fuerza y de costado". Partiendo de que se trata de un caso de "inidoneidad absoluta" (y no "relativa"), esto es imposibilidad absoluta de causar la muerte, y argumentando, entre otras consideraciones, el alineamiento del nuevo Código penal "con la consideración objetiva de la tentativa, precisando la efectiva puesta en peligro del bien jurídico al que el tipo está llamado a proteger" el tribunal absuelve al sujeto de la tentativa de homicidio de que era acusado.

Obsérvese, sin embargo, cómo, en la perspectiva seguida, no es el juicio del hombre medio ex ante (ni en la posición del autor ni en ninguna otra posición) lo que fundamenta la exclusión de un peligro, sino el juicio ex post del experto en balística. Pero añádase además lo siguiente: en toda tentativa fallida ex definitione se podrá concluir por un sujeto lo suficientemente experto en los hechos y las leyes científicas aplicables al caso que no había peligro. Sólo hará falta encontrar a ese experto (que, por lo demás, a veces habrá de juzgar sobre la base de una compleja diversidad de factores, y no, como aquí, sobre la exclusiva base de la configuración del arma y la distancia de la víctima).

La tesis seguida convierte en criterio de la tentativa punible al juicio ex post de un experto "medio" (esto es, "asequible"); en cambio, los casos de tentativa fallida en los que un sujeto así configurado no supiera individualizar la causa por la que el resultado no se ha producido seguirían siendo punibles. Pero conviene significar que tal causa necesariamente ha de haber existido, pues de lo contrario por fuerza se habría producido el resultado. Obsérvese cómo la lógica de esta vía conduce, en realidad, a la impunidad de toda tentativa fallida. Sin embargo, es bastante plausible sostener lo contrario: los supuestos en que un hombre medio, en la posición

${ }^{47}$ Repertorio Actualidad Penal Audiencias 303. 
del autor, advierte peligro para el bien jurídico tienen una evidente dimensión social de sentido (virtualidad de desestabilización de la norma) y un Derecho penal preventivo (desde luego con pretensión de integración) no puede ignorarlos. Probablemente, la solución absolutoria (respecto a la tentativa de homicidio) de la Audiencia Provincial de Zaragoza se vió considerablemente facilitada por el hecho de poder castigar al acusado por el delito de tenencia ilícita de armas. Es más que dudoso que la solución hubiera sido la misma si ello hubiera implicado la total impunidad del mismo. Tal proceder implicaría, desde luego, mezclar cuestiones distintas. Pero es, a mi entender, bastante revelador de la real naturaleza de la discusión en este punto.

15. En todo caso, el art. 16 CP no sólo incide en la específica dogmática de la tentativa, sino que configura, de algún modo, el modo de concebir la realización típica dolosa, en general. Es sabido que, tanto en Alemania como en España, existían corrientes de opinión singularmente reticentes a la aceptación de la existencia de un principio de "imputación objetiva" en el delito doloso, en el entendimiento de que los desarrollos de la teoría del riesgo jurídicamente desaprobado y su realización en el resultado eran aplicables sólo a los delitos imprudentes ${ }^{48}$. Pues bien, por pura coherencia con lo señalado para la tentativa parece clara la necesidad de realizar, también en el delito doloso consumado, un juicio sobre la desaprobación jurídica del riesgo (desde un punto de vista ex ante) y sobre su efectiva realización en el resultado producido, de modo separado del juicio sobre su imputación subjetiva ${ }^{49}$. Quiere ello significar que el tipo objetivo del delito doloso y el del imprudente deben considerarse estructuralmente coincidentes. Ciertamente, ello no tiene que conducir a desconocer que existen elementos que, pese a ser tenidos normalmente en cuenta sólo a efectos de imputación subjetiva, poseen, por el significado transcategorial de la mayor parte de las connotaciones de la acción humana, también trascendencia en el plano objetivo. Por ejemplo, la existencia de una conducción final no es sólo un elemento de la imputación subjetiva, sino que también debe ser tenido en cuenta en la configuración del riesgo objetivamente relevante. Con todo, es innegable una repercusión de la nueva redacción legal del régimen de la tentativa: da la razón a quienes entendían que es posible que quien "dolosamente" causó (o contribuyó a causar) un resultado dolosamente no sea, pese a todo, sancionado, al no constituir su conducta un riesgo jurídicamente desaprobado. Cuestión aparte es que, en tal caso, de causación efectiva pero ausencia de un riesgo jurídicamente desaprobado, sólo pueda hablarse de "dolo" en un sentido impropio, por cuanto el objeto del dolo (y, por tanto, elemento esencial determinante de su concurrencia) es precisamente la existencia de tal riesgo jurídicamente desaprobado.

\footnotetext{
48 Habia sido muy determinante en este sentido el artículo de KAUFMANN, Armin, "¿Atribución objetiva en el delito doloso?" (trad. Cuello Contreras), ADPCP 1985, pp. 807 y ss.

Cfr. en este sentido CEREZO MIR, Curso, I, $5^{3}$ ed., p. 11.
} 